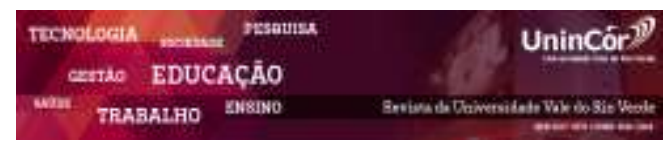

Revista da Universidade Vale do Rio Verde ISSN: 1517-0276 / EISSN: 2236-5362 Vol. 16 | n. 1 | Ano 2018

Lauana Aparecida Santos Universidade Federal de Alfenas-UNIFAL lauanasantos20@gmail.com

\section{A MICROBIOTA INTESTINAL E SUA RELAÇÃO COM O SISTEMA IMUNOLÓGICO}

\section{RESUMO}

A microbiota intestinal constitui em um conjunto de microrganismos que estão presentes no intestino. O processo de colonização do trato-gastrointestinal por estes microrganismos inicia-se ao nascimento do neonato. A presença destes microrganismos na mucosa intestinal confere vários benefícios ao hospedeiro dentre eles a estimulação do sistema imunológico. Desse modo, o objetivo deste trabalho foi descrever a importância da microbiota intestinal e sua relação com o sistema imunológico do hospedeiro. O presente estudo consistiu de uma revisão de literatura, nos quais foram utilizados artigos em diferentes idiomas. Pode-se concluir que a microbiota intestinal promove estímulos no sistema imune do hospedeiro que são essenciais para conferir proteção. O desequilíbrio na composição microbiana comensal pode ocasionar várias doenças ao hospedeiro, mas ainda há poucos estudos explicando este processo. Desse modo, compreender o papel da microbiota oferece subsídios para a descoberta de novas condutas clínicas para o tratamento de doenças.

Palavras-chave: Sistema imunológico. Microrganismos comensais. Microbiota intestinal. Mucosa intestinal. Tratogastrointestinal.

\section{MICROBIOTA INTESTINAL AND ITS RELATIONSHIP WITH THE IMMUNOLOGICAL SYSTEM}

\begin{abstract}
An intestinal microbiota constitute a set of microorganisms that are present not intestine. The process of colonization of the gastrointestinal tract by these microorganisms begins at the birth of the newborn. The presence of these microorganisms in the intestinal mucosa confers several benefits to the host, among them the stimulation of the immune system. Thus, the objective of this work was to describe the importance of the intestinal microbiota and its relation with the host's immune system. The present study consisted of a review of the literature, in which articles were used in different languages. It can be concluded that the intestinal microbiota promotes stimuli in the host immune system that are essential to confer protection. Unbalance in the commensal microbial composition can cause several diseases to the host, but there are still few studies explaining this process. In this way, understanding the role of the microbiota provides support for the discovery of new clinical behaviors for the treatment of diseases.
\end{abstract}

Keywords: Immune system. Commensal microorganisms. Gastrointestinal. Microbiota intestinal. Intestinal mucosa. 


\section{INTRODUÇÃO}

A microbiota intestinal constitui em um conjunto de microrganismos que estão presentes no intestino e cuja composição varia ao longo do trato-gastrointestinal (TGI) e entre o lúmen e mucosa intestinal. Os microrganismos anaeróbios facultativos e estritos compõem a microbiota intestinal. Foram descritos em estudos que mais de 50 filos estão presentes no intestino humano, no entanto dois destes são mais prevalentes, os filos Bacteroidetes e Firmicutes (JIMÉNEZ et al., 2008). Estudos descrevem que a mucosa intestinal é colonizada por mais de 1000 espécies de bactérias, no qual podendo compor também fungos e vírus (BULL; PLUMMER, 2014).

A colonização do trato-gastrointestinal (TGI) humano tem seu inicio ao nascimento, após o parto é rapidamente colonizado. Isto ocorre devido ao neonato passar pelo canal vaginal e sendo exposto aos microrganismos que colonizam a mucosa vaginal materna. Durante os primeiros anos de vida da criança os microrganismos que colonizam o TGI possuem uma composição variável e após os 2 e 3 anos de idade começa a ser estável, sendo comparada com a de um adulto (BULL; PLUMMER, 2014; LEY et al., 2005).
Os microrganismos que dominam a microbiota intestinal são anaeróbios facultativos que incluem os gêneros Lactobacillus, Enterococcus, Streptococcus e Enterobacteriaceae. Os anaeróbios estritos que dominam o TGI incluem Bacteroides, Eubacterium,

Bifidobacterium, Fusobacterium, Peptostreptococcus e Atopobium. Estes são referidos como simbióticos intestinais em decorrência de possuírem uma relação mutualística com o organismo humano (BULL; PLUMMER, 2014).

As células do tecido linfóide associado à mucosa intestinal (GALT) inclui as células apresentadoras de antígeno, linfócitos B e T, células epiteliais e outras que estão em contínuo contato com a microbiota intestinal. No intestino dos mamíferos, as placas de Peyer possuem um papel fundamental no controle da interação do sistema imunológico do hospedeiro com a microbiota intestinal. Nestes locais, as células dendríticas tem a capacidade de apresentar os antígenos excretados pela microbiota intestinal e induzir as células a produzirem uma resposta imunológica (GEUKING et al., 2014).

Os antígenos que são provenientes da microbiota intestinal estimulam o desenvolvimento dos órgãos linfóides 
associados às mucosas (GALT). Dessa maneira, a microbiota intestinal é uma fonte importante de antígenos e possuem a capacidade de manutenção de um estado de homeostasia no hospedeiro. Visto que, a mucosa intestinal é porta de entrada de inúmeros antígenos e a microbiota intestinal é capaz de impedir a colonização do TGI por outros microrganismos que são potencialmente patogénicos e também estimular a resposta imunológica em nível de mucosa (ZEUTHEN et al., 2010).

A microbiota intestinal possuem a capacidade de modular a imunidade a nível de mucosa. Isto, pode afetar as respostas imunológicas sistêmicas por meio da modulação na expansão extra-intestinal dos linfócitos $\mathrm{T}$ levando ao desenvolvimento de tolerância oral e controle da inflamação (KIEPER et al., 2005; SAMUELSON et al., 2015). Estudos descrevem que os microrganismos comensais do intestino induz a manutenção de células importantes para a imunidade de mucosa (SAMUELSON et al., 2015).

Diante disso, faz-se importante discutir como que a microbiota intestinal estabelece uma relação benéfica com $o$ hospedeiro estimulando o seu sistema imunológico e por fim o desequilíbrio na composição destes pode estar relacionado com algumas doenças. $\mathrm{O}$ presente estudo tem por objetivo descrever a importância da microbiota intestinal e sua relação com o sistema imunológico na proteção do organismo do indivíduo.

\section{MÉTODOS}

O presente estudo consistiu da consulta, revisão e leitura de banco de dados (Scielo, PubMed, Cochrane e outros) de artigos científicos. Foram utilizados artigos em diferentes idiomas e não se utilizou artigos com a descrição do tema muito restritos.

\section{REVISÃO DE LITERATURA}

\section{O trato gastrointestinal e a mucosa intestinal}

A superfície de contato do trato gastrointestinal humano é de aproximadamente de $200 \mathrm{~m}^{2}$. No qual, este se apresenta como uma rede complexa e dinâmica de interações entre as células que compõem a mucosa intestinal. Atuando como uma camada semipermeável que permiti a absorção de nutrientes e macromoléculas que são necessárias ao metabolismo humano. Em contrapartida, protege o indivíduo de microrganismos que podem ser potencialmente invasivos. Tais funções são desempenhadas em um ambiente que é colonizado por diversos microrganismos comensais (LOPETUSO et al., 2014). Os componentes celulares e extracelulares 
compõem a mucosa intestinal. $\mathrm{Na}$ parte celular é definida por um epitélio intestinal e uma lâmina própria adjacente. Neste epitélio contém células de Paneth interpostas produzindo peptídios antimicrobianos, enterócitos absortivos, células caliciformes (que produzem o muco) e as células enteroendócrinas (DE SANTIS et al., 2015). As células que compõem a lâmina intestinal são células dendríticas (DC), células intraepiteliais (IEDCS), macrófagos, linfócitos intra-epiteliais, células $\mathrm{T}$ reguladoras $(\mathrm{T}$ Regs), linfócitos TCD4+ e B (DE SANTIS et al., 2015; RESCIGNO, 2011).

O muco representa os componentes extracelulares representando como a primeira barreira física contra os microrganismos e exercendo um papel importante, como a proteção do epitélio. As enzimas digestivas presentes no lúmem evitam a adesão de microrganismos às células que revestem a mucosa e impedindo a invasão. As imunoglobilinas secretoras complementam está função estando representada pela IgA. O muco também facilita a passagem de nutrientes para o organismo e é lubrificante para a motilidade intestinal (DE SANTIS et al., 2015; SANTOS et al., 2016).

O muco é composto por duas camadas, uma interna e outra externa. A camada interna é fortemente aderida às células epiteliais. Já a camada externa é mais espessa, flexível e menos aderente. A mucina altamente glicosilada desempenha um papel de constituição da camada de muco. A função do muco vai além do que exercer uma barreira. $\mathrm{O}$ seu conteúdo em glicanos e mucina serve de alimento para os microrganismos e favorece a ligação destes a mucosa e provavelmente de seleção de espécies microbianas que são específicas e essenciais para a manutenção da integridade e homeostase intestinal (OUWERKERK et al., 2013; VIGGIANO et al., 2015).

\section{A microbiota intestinal}

O trato-gastrointestinal humano apresenta diferentes composições bacterianas, sendo estas definidas geneticamente ou por características individuais e ambientais. $\mathrm{O}$ modo de nascimento, idade, hábitos alimentares contribuem para que ocorra uma variabilidade intra e interindividual (MORAES et al., 2014). A maior parte do TGI é colonizada por bactérias, que se distribuem em mais de 1000 espécies. Sendo, microrganismos autóctones (permanentes) e alóctones (transitórios). Cerca de $60 \%$ destes microrganismos não são cultiváveis em técnicas de cultura convencionais (SAMUELSON et al., 2015).

Os estudos demonstraram que quatro filos colonizam o TGI humano sendo: Firmicutes, Bacteroidetes, Proteobacteria e Actinobacteria que representam $98 \%$ da microbiota intestinal (LOPETUSO et al., 2014). Estima-se que 30-40 espécies de bactérias dominam o ecossistema da microbiota intestinal, nas quais compreendem os gêneros 
Bacteroides, Bifidobacterium, Eubacterium, Fusobacterium, Clostridium e Lactobacillus (MCLOUGHLIN; MILLS; 2011).

A microbiota não é somente distribuída ao longo do TGI na mucosa saudável, mas entre a mucosa e o lúmem intestinal. Na mucosa gástrica encontra-se uma concentração microbiana de $10^{3}$ unidades formadoras de colônia (CFU/ mL), no intestino delgado há $10^{2}$ a $10^{9}$ (CFU/ mL) e no intestino grosso tem-se $10^{4}$ a $10^{12}(\mathrm{CFU} / \mathrm{mL})$. A grande quantidade de microrganismos no intestino grosso é explicada pela motilidade intestinal lenta e a microbiota ser mais estável quando se compara com os demais locais (LOZUPONE et al., 2012).

Os microrganismos que colonizam o TGI possuem a capacidade de conservar e promover o bem estar e a ausência de doenças. Sendo capaz de formar uma barreira contra patógenos invasores e desse modo, potencializando os mecanismos de defesa, melhorando a imunidade do hospedeiro e estimulando o sistema imunológico (LOPETUSO et al., 2014; LOZUPONE et al., 2012).

Nos recém-nascidos verifica-se que a microbiota contém poucas ou quase nenhuma espécie de bactérias. Nos adultos contém cerca de centenas de diferentes espécies de bactérias formando um complexo ecossistema. O momento do parto já começa a influenciar a colonização do TGI e também a lactação (SANTOS et al., 2016).
A utilização de antibióticos, mudanças na dieta, quimioterapia para o câncer $\mathrm{e}$ processos infeciosos do TGI podem alterar permanentemente ou transitoriamente $\mathrm{o}$ ecossistema intestinal. Tais alterações levam a disbiose intestinal, que consiste em desequilíbrio microbiano no interior do TGI (HOOPER et al., 2012; HOOPER; MACPHERSON, 2010; SAMUELSON et al., 2015). Disbiose caracteriza-se pela perda ou diminuição na quantidade de microrganismos que trazem benefícios e/ou deslocamento da composição microbiana, ou seja, favorece o aumento de microrganismos patogênicos. A alteração do perfil metabólico e/ou aumento de processo inflamatório da mucosa do hospedeiro pode ocorrer em decorrência da disbiose (SAMUELSON et al., 2015).

\section{Relação da microbiota intestinal e o sistema imunológico}

A microbiota intestinal estabelece uma relação de mutualismo com o hospedeiro, pois o TGI humano serve de habitat para estes microrganismos. Esta relação mutualística é favorecida pela temperatura ótima corporal do hospedeiro e a disponibilidade de nutrientes. No entanto, os microrganismos comensais auxiliam na quebra de nutrientes e faz síntese de vitaminas essências. Desse modo, há benefício tanto para o hospedeiro quanto aos microrganismos 
(HUDAULT et al., 2001; NUDING et al., 2013).

Os componentes da parede bacteriana são reconhecidos, tanto de microrganismos comensais quanto de patogênicos. Os componentes que podem ser reconhecidos por receptores de reconhecimento de padrões (PRR), Toll-like (TRLs) e nucleotídeo de ligação de receptores de domínio de oligomerização (NODs) são; LPS, peptidioglicano e flagelina. Entretanto, para os microrganismos comensais estes são tolerados e os patogênicos são reconhecidos e combatidos pelo sistema imunológico (OTTE et al., 2003).

As estimulações de PRR pelos microrganismos comensais resultam na produção de linfopoetina estromal tímica (TSLP). O TSLP tem a função de melhorar a indução da secreção do fator de ativação celular de linfócitos $\mathrm{B}$ que promovem a secreção de $\operatorname{Ig}$ A sérica. A $\operatorname{Ig}$ A produzida é secretada no lúmen intestinal e pode levar a alterações na composição e funções da microbiota intestinal (JOHANSSON et al., 2008).

Os microrganismos comensais possuem a capacidade de modular a imunidade em nível de mucosa intestinal. Estes microrganismos comensais afetam as repostas imunológicas sistêmicas pela modulação na expansão extraintestinal das células $\mathrm{T}$ ocasionando $\mathrm{O}$ desenvolvimento de tolerância oral e controle da inflamação (KIEPER et al., 2005;
SAMUELSON et al., 2015). Segundo Samuelson et al. (2015), relatam que os microrganismos que compõem a microbiota intestinal induz a manutenção de células importantes para imunidade de mucosa tendo a expansão de células T CD4+ e resposta Th1, Th2 e Th17.

Desse modo, verifica-se que os microrganismos que compõem a microbiota intestinal promovem estímulos ao sistema imune do hospedeiro e isto favorece a colonização. Ambas partes se beneficiam desta inter-relação. A ocorrência de manutenção da tolerância oral e controle da inflamação pela microbiota intestinal reforça a ideia que favorece a ocorrência de homeostasia no TGI humano.

\section{DISCUSSÃO}

O sistema imunológico reconhece os microrganismos comensais intestinais e desencadeia uma resposta imunológica (SAMUELSON et al., 2015). A interação que ocorre com as células do epitélio intestinal e a microbiota pode gerar duas respostas imunes: imunidade protetora contra patógenos e a ocorrência de tolerância imunológica de não microrganismos patogênicos (CHICHLOWSKI et al., 2015; SAMUELSON et al., 2015).

De acordo com Weng e Walker (2013), o desenvolvimento da tolerância 
imunológica ocorre após um contato prévio com o antígeno e isto representa um estado imunológico tanto local quanto sistêmico de não reação imune efetora, após o sistema imune ser desafiado subsequentemente. Estudos tratam que a colonização no inicio da vida é o ponto chave da ocorrência de tolerância imunológica, mas ainda não é totalmente compreendida.

Os efeitos supressores sobre a resposta imunológica incluem os linfócitos T CD4+ FoxP3+ Treg, linfócitos T CD8+ dos quais produzem IL10 e TGF- $\beta$. As células dendríticas tolerogênicas, células supressoras mieloídes e IL10 que são produzidas pelos linfócitos B também atuam nos efeitos de supressão (BELKAID; OLDENHOVE 2008). Os linfócitos T CD4 + FoxP3 + Treg possuem um papel dominante na manutenção de tolerância imunológica e na ocorrência de supressão da resposta imune excessiva. Estas células estão mais presentes na lâmina própria intestinal e nos nódulos linfáticos periféricos e até mesmo no baço; esta função aplicada a estas células pode ser confirmada pelo local onde estão em mais abundancia (WENG; WALKER, 2013).

Estudos indicam que quando a microbiota intestinal está alterada pode estar associada a doenças inflamatórias, infecção viral crônica, obesidade e até mesmo o câncer. No entanto, ainda pouco se sabe sobre o papel destes microrganismos no processo de desenvolvimento destas doenças (KAMADA et al., 2010).

A maioria dos microrganismos comensais está restrita ao lúmen intestinal, no entanto uma pequena porcentagem pode penetrar para o interior da camada da mucosa e assim colonizá-lo. Isto explica que as respostas das células do sistema imunológico estão associadas com estes microrganismos, nos quais confere imunidade da mucosa, esta função pode ser complementada pela $\operatorname{IgA}$ secretora que faz parte da primeira linha de defesa contra os patógenos (VAISHNAVA et al. 2011; HILL et al., 2010).

Segundo Hill et al. (2010), a microbiota intestinal induz a ativação de células Th17 e foi possível observação da produção de citocinas a partir desta ativação. Todavia, alguns microrganismos comensais podem provocar respostas inflamatórias imunes que dependendo do contato conferem a proteção tecidual. Desse modo, ocorre uma interação dos microrganismos comensais com o sistema imunológico do hospedeiro.

\section{CONCLUSÃO}

Diante do que foi exposto, verifica-se que a microbiota intestinal promove estímulos no sistema imune do hospedeiro favorecendo a sua colonização. Desse modo, o hospedeiro por sua vez se beneficia de diversas formas na manutenção de tolerância a microbiota 
intestinal e reforçando a ideia de que favorece a homeostasia no TGI.

A manutenção da integridade da mucosa é necessária para a manutenção desta homeostasia no intestino. A ocorrência de um desequilíbrio conduz a ativação do sistema imune e levando a indução de inflamação. Por fim, ressaltando a importância da microbiota

\section{REFERÊNCIAS}

BELKAID, Y; OLDENHOVE, G. Tuning microenvironments: induction of regulatory $\mathrm{T}$ cells by dendritic cells. Immunity. 2008;29:362-371.

BULL, MJ; PLUMMER, NT. Part 1: The Human Gut Microbiome in Health and Disease. Integr Med (Encinitas). 2014;13(6):17-22,.

CHICHLOWSKI, M; RUDOLPH, C. Visceral Pain and Gastrointestinal Microbiome. J

Neurogastroenterol Motil. 2015;21(2): 2093-0879.

DE SANTIS, S. et al. Nutritional Keys for Intestinal Barrier Modulation. Front. Immunol. 2015; 6:612.

GEUKING, MB. et al. The interplay between the gut microbiota and the immune system. Gut Microbes. 2014; 5(3):411-418.

HILL, DA. et al. Metagenomic analyses reveal antibiotic-induced temporal and spatial changes in intestinal microbiota with associated alterations in immune cell homeostasis. Mucosal Immunol. 2010;3:148-158.

HOOPER, LV; LITTMAN, DR; MACPHERSON, AJ. Interactions between the microbiota and the immune system. Science. 2012;336:1268-1273,.

HOOPER, LV; MACPHERSON, AJ. Immune adaptations that maintain homeostasis with the intestinal microbiota. Nat. Rev. Immunol. 2010;10: 159-169.

HUDAULT, S; GUIGNOT, J; SERVIN, AL. Escherichia coli strains colonising the gastrointestinal tract protect germ-free mice against Salmonella typhimurium infection. Gut. 2001;49:47-55,. intestinal para o hospedeiro, como a capacidade de formar barreiras contra microrganismos invasores, potencialização dos mecanismos de defesa e estimulando a resposta imune, mais estudos na compreensão do papel da microbiota oferecerão ferramentas para descoberta de novas condutas clínicas para doenças principalmente gastrointestinal.

JIMÉNEZ, E; MARÍN, ML; MARTÍN, R. et al. Is meconium from healthy newborns actually sterile? Res Microbiol. 2008; 159(3):187-193,.

JOHANSSON, ME. et al.: The inner of the two Muc2 mucin-dependent mucus layers in colon is devoid of bacteria. Proc Natl Acad Sci. 2008; 105: 15064 15069.

KAMADA, N; SEO, SU; CHEN, GY; NUNEZ, G. Role of the gut microbiota in immunity and inflammatory disease. Nat Rev Immunol. 2013;13: 321-335.

KIEPER, WC. et al. Recent immune status determines the source of antigens that drive homeostatic T cell expansion. J. Immunol. 2005;174:3158-3163,.

LEY, RE. et al. Obesity alters gut microbial ecology. Proc Natl Acad Sci USA. 2005;102(3):11070-11075.

LOPETUSO, LR et al. The gastrointestinal microbiome e Functional interference between stomach and intestine. Best Practice \& Research Clinical Gastroenterology. 2014;28: 995-1002.

LOZUPONE, CA et al. Diversity, stability and resilience of the human gut microbiota. Nature. 2012; 489: $220-230$.

MCLOUGHLIN, RM; MILLS, KHG. Influence of gastrointestinal commensal bacteria on the immune responses that mediate allergy and asthma. J. Allergy Clin. Immunol. 2011;127:1097-1107.

NUDING, S. et al. The Host and the Flora. Dig Dis. 2013;31: 286-292.

OTTE, JM; KIEHNE, K; HERZIG, KH.

Antimicrobial peptides in innate immunity of the human intestine. J Gastroenterol. 2003;38:717- 726.

OUWERKERK, JP; DE VOS, WM; BELZER, C. Glycobiome: bacteria and mucus at the epithelial 
interface. Best Pract Res Clin Gastroenterol.

2013;27:25-38.

RESCIGNO, M. The intestinal epithelial barrier in the control of homeostasis and immunity. Trends Immunol. 2011;32:256-64.

SAMUELSON, DR. et al. Regulation of lung immunity and host defense by the intestinal microbiota. Front. Microbiol. 2015;6:1085.

SANTOS, LA. et al. Avaliação da resposta imune in vitro contra os antígenos totais de Escherichia coli. Dissertação (Pós-graduação). Instituto de Ciências Biomédicas, Universidade Federal de Alfenas, MG, 2016.

VAISHNAVA, S. et al. The antibacterial lectin RegIII gamma promotes the spatial segregation of microbiota and host in the intestine. Science. 2011;334:255-258.

VIGGIANO, D. et al. Gut barrier in health and disease: focus on childhood. European Review for Medical and Pharmacological Sciences. 2015;19:1077-1085.

WENG, M; WALKER, WA. The role of gut microbiota in programming the immune Phenotype. J Dev Orig Health Dis. 2013;1(4).

ZEUTHEN, LH. et al. Lactobacillus acidophilus induces a slow but more sustained chemokine and cytokine response in naïve foetal enterocytes compared to commensal Escherichia coli. BMC Immunology. 2010;11(2).

\section{Lauana Aparecida Santos}

Mestra em Biociências Aplicadas à Saúde pela Universidade Federal de Alfenas. 